\title{
Analysis of the genetic diversity of Lonicera japonica Thumb. using inter-simple sequence repeat markers
}

\author{
H.Y. He ${ }^{1,2}$, D. Zhang ${ }^{1}$, H. Qing ${ }^{1,2}$ and Y. Yang ${ }^{3}$ \\ ${ }^{1}$ Key Laboratory of Mountain Surface Processes and Ecological Regulation, \\ Institute of Mountain Hazards and Environment, Chinese Academy of Sciences, \\ Chengdu, China \\ ${ }^{2}$ University of Chinese Academy of Sciences, Beijing, China \\ ${ }^{3}$ Yibin Branch of Sichuan Provincial Tobacco Company, Yibin, China \\ Corresponding author: D. Zhang \\ E-mail: daniezhang@imde.ac.cn \\ Genet. Mol. Res. 16 (1): gmr16019338 \\ Received September 21, 2016 \\ Accepted September 21, 2016 \\ Published January 23, 2017 \\ DOI http://dx.doi.org/10.4238/gmr16019338
}

Copyright (C) 2017 The Authors. This is an open-access article distributed under the terms of the Creative Commons Attribution ShareAlike (CC BY-SA) 4.0 License.

\begin{abstract}
Inter-simple sequence repeats (ISSRs) were used to analyze the genetic diversity of 21 accessions obtained from four provinces in China, Shandong, Henan, Hebei, and Sichuan. A total of 272 scored bands were generated using the eight primers previously screened across 21 accessions, of which 267 were polymorphic (98.16\%). Genetic similarity coefficients varied from 0.4816 to 0.9118 , with an average of 0.6337 . The UPGMA dendrogram grouped 21 accessions into two main clusters. Cluster A comprised four Lonicera macranthoides Hand. Mazz. accessions, of which J10 was found to be from Sichuan, and J17, J18, and J19 were found to be from Shandong. Cluster B comprised 17 Lonicera japonica Thumb. accessions, divided into the wild accession J16 and the other 16 cultivars. The results of the
\end{abstract}


principal component analysis were comparable to the cluster analysis. Therefore, the ISSR markers could be effectively used to distinguish interspecific and intraspecific variations, which may facilitate identification of Lonicera japonica cultivars for planting, medicinal use, and germplasm conservation.

Key words: Genetic diversity; Lonicera japonica Thumb.; Inter-simple sequence repeat

\section{INTRODUCTION}

Lonicera japonica Thumb. has been used for thousands of years as traditional Chinese medicine owing to its bacteriostasis (Tang et al., 2008), antitumor (Liu et al., 2012), antioxidant (Gong et al., 2006), anti-endotoxin (Yang et al., 2012), antiinflammatory (Kang et al., 2004; Chen et al., 2012), antiviral (Yan et al., 1998), proimmune (Cui, 2011), and blood sugar-lowering effects (Liang et al., 2011). In commercial production, many species from the family Caprifoliaceae, including Lonicera similis Hemsl., Lonicera macranthoides Hand.-Mazz., Lonicera acuminata Wall., and Lonicera hypoglauca Miq., have been applied as Lonicera japonica. The Chinese pharmacopoeia stipulates that Lonicera japonica Thumb. must be the only source of this plant, whereas different cultivars are the main source of commercial herbs of Lonicera japonica.

In the past four decades, researchers have developed several molecular marker techniques, including inter-simple sequence repeat (ISSR) (Zietkiewicz et al., 1994). ISSR is rapid, inexpensive, simple, and efficient DNA marker method that does not require prior knowledge of the DNA sequence or large amounts of starting DNA template. ISSR is widely used for germplasm identification, fingerprint construction, and genetic diversity and relationship analyses (Charters et al., 1996; Blair et al., 1999; Chen et al., 2008; Smolik et al., 2010; Wang et al., 2012; Wang et al., 2013; Li et al., 2013; Sunar et al., 2016). In this study, we aimed to establish a method for identification of real Lonicera japonica for planting, medicinal use, and germplasm conservation by analyzing the genetic diversity of 17 Lonicera japonica accessions (including 16 cultivar accessions and one wild accession) and four Lonicera macranthoides accessions.

\section{MATERIAL AND METHODS}

\section{Plant sample collection and extraction of DNA}

In this study, seedlings were collected from different provinces in China, Shandong, Henan, Hebei, and Sichuan (as listed in Table 1) and planted in experimental plots in the Institute of Mountain Hazards and Environment, Chinese Academy of Sciences. Total genomic DNA was extracted from young leaves using the CTAB (hexadecyltrimethylammonium bromide) method, with slight modifications. DNA quality and quantity were evaluated on $2 \%$ agarose gels and a Nanodrop 2000 ultramicrospectrophotometer. The final concentration of all DNA samples was adjusted to $20 \mathrm{ng} / \mu \mathrm{L}$, and samples were stored at $-20^{\circ} \mathrm{C}$ for further analysis.

Genetics and Molecular Research 16 (1): gmr16019338 


\begin{tabular}{|c|c|c|c|c|c|}
\hline No. & Sources & Species & No. & Sources & Species \\
\hline $\mathrm{J} 1$ & Shangdong & L. japonica & $\mathrm{J} 12$ & Shangdong & L. japonica \\
\hline $\mathrm{J} 2$ & Shangdong & L. japonica & $\mathrm{J} 13$ & Shangdong & L. japonica \\
\hline $\mathrm{J} 3$ & Shangdong & L. japonica & J14 & Shangdong & L. japonica \\
\hline $\mathrm{J} 4$ & Shangdong & L. japonica & $\mathrm{J} 15$ & Henan & L. japonica \\
\hline J5 & Shangdong & L. japonica & J16 & Sichuan & L. japonica \\
\hline J6 & Shangdong & L. japonica & $\mathrm{J} 17$ & Sichuan & L. macranthoides \\
\hline J7 & Shangdong & L. japonica & $\mathrm{J} 18$ & Sichuan & L. macranthoides \\
\hline J8 & Shangdong & L. japonica & J19 & Sichuan & L. macranthoides \\
\hline J9 & Shangdong & L. japonica & $\mathrm{J} 20$ & Sichuan & L. japonica \\
\hline $\mathrm{J} 10$ & Shangdong & L. macranthoides & $\mathrm{J} 21$ & Hebei & L. japonica \\
\hline J11 & Shangdong & L. japonica & & & \\
\hline
\end{tabular}

\section{Amplification of DNA by ISSR-polymerase chain reaction (PCR)}

ISSR amplification was performed in a $20-\mu \mathrm{L}$ volume containing $10 \mu \mathrm{L} 2 \mathrm{X}$ PCR Mix, $3 \mu \mathrm{L}$ genomic DNA, $0.8 \mu \mathrm{L} 10 \mu \mathrm{M}$ primers, and $6.2 \mu \mathrm{L}$ sterile water. The amplification reactions were carried out under the following conditions: 5 min at $94^{\circ} \mathrm{C}$, followed by $30 \mathrm{~s}$ at $94^{\circ} \mathrm{C}, 30 \mathrm{~s}$ at the annealing temperature (specific to each primer), $90 \mathrm{~s}$ at $72^{\circ} \mathrm{C}$ for 36 cycles, and $7 \mathrm{~min}$ at $72^{\circ} \mathrm{C}$. PCR products were separated by electrophoresis using $6 \%$ polyacrylamide gels, stained with silver nitrate, and imaged using a digital camera. Eight primers (Table 2) from a total of 27 ISSR primers tested (published by Columbia University) were selected, and their respective annealing temperatures were optimized for ISSR amplification. PCR amplification of all selected primers was repeated in triplicate.

\section{Statistical analysis}

ISSR-amplified fragments with the same mobility according to molecular weight (bp) were scored manually for band presence (marked as 1) or absence (marked as 0). The percentage of polymorphic bands was measured using the POPGENE 32 program for genetic diversity analysis. A dendrogram was constructed based on SM similarity coefficients using the unweighted pair group method with arithmetic mean (UPGMA) with the SAHN module of NTSYS-pc 2.10. A principal coordinate analysis (PCA) was used to construct a two-dimensional array of eigenvectors in the DCENTER module of NTSYS-pc 2.10 (Rohlf, 2000).

\section{RESULTS}

\section{Genetic diversity}

A total of 272 scored bands were generated using eight primers previously screened across the 21 accessions. The number of amplified bands per primer ranged from 24 (UBC815) to 41 (UBC840; Table 2). Of the 272 amplified bands, 267 were polymorphic $(98.16 \%)$. The percentage of polymorphic bands across the primers ranged from $95.83 \%$ 
(UBC815) to $100 \%$ (UBC808, UBC840, and UBC841; Table 2). The band sizes ranged from approximately 200 to $2500 \mathrm{bp}$.

Table 2. ISSR primers used in this study and some summary results.

\begin{tabular}{|c|c|c|c|c|c|}
\hline Primer & Sequence (5'-3') & $\mathrm{T}\left({ }^{\circ} \mathrm{C}\right)$ & No. of bands scored & No. of polymorphic bands & Percentage of polymorphic bands (PPB) \\
\hline UBC 808 & $(\mathrm{AG})_{8} \mathrm{C}$ & 52.2 & 26 & 26 & 100.00 \\
\hline UBC 811 & $(\mathrm{GA})_{8} \mathrm{C}$ & 47.2 & 39 & 38 & 97.44 \\
\hline UBC 815 & $(\mathrm{CT})_{8} \mathrm{G}$ & 49.2 & 24 & 23 & 95.83 \\
\hline UBC 827 & $(\mathrm{AC})_{8} \mathrm{G}$ & 53.4 & 36 & 35 & 97.22 \\
\hline UBC 834 & $(\mathrm{AG})_{8} \mathrm{YT}$ & 48 & 31 & 30 & 96.77 \\
\hline UBC 835 & $(\mathrm{AG})_{8} \mathrm{YC}$ & 49.2 & 38 & 37 & 97.37 \\
\hline UBC 840 & $(\mathrm{GA})_{8} \mathrm{YT}$ & 47.2 & 41 & 41 & 100.00 \\
\hline UBC 841 & $(\mathrm{GA})_{8} \mathrm{YC}$ & 48 & 37 & 37 & 100.00 \\
\hline \multicolumn{3}{|l|}{ In total } & 272 & 267 & 98.16 \\
\hline
\end{tabular}

\section{Genetic similarity coefficients}

The SM similarity coefficients across 21 accessions ranged from 0.4816 to 0.9118 (as listed in Table 3), with an average of 0.6337 . The maximum similarity coefficient was observed between J17 and J18 (0.9118), whereas the minimum similarity coefficient was observed between $\mathrm{J} 5$ and $\mathrm{J} 17$ ( 0.4816$)$.

\section{Cluster analysis}

Figure 1 shows the UPGMA tree constructed from 21 accessions. When the similarity coefficient was 0.54 , the UPGMA dendrogram grouped the 21 accessions into two main clusters. Cluster A comprised four Lonicera macranthoides accessions, and cluster B comprised 17 Lonicera japonica accessions. When the similarity coefficient was 0.58 , cluster A could be divided into two subclusters: the A1 subcluster, including accessions $\mathrm{J} 17, \mathrm{~J} 18$, and $\mathrm{J} 19$; and the $\mathrm{A} 2$ subcluster, including accession J10. Accession J10 from Sichuan was distinguished from accessions J17, J18, and J19 from Shandong. When the similarity coefficient was $0.61,17$ accessions in cluster B could be divided into two subclusters: the B1 subcluster, including accessions $\mathrm{J} 2$, J4, and $\mathrm{J} 11$; and the B2 subcluster, including the other 14 accessions. When the similarity coefficient was 0.68 , subcluster B2 could be subdivided into two groups: group B21, including the wild accession J16; and group B22, including the other 13 accessions.

\section{PCA}

The SM genetic similarity coefficients of 21 accessions were used to carry out PCA of a two-dimensional array of eigenvectors (Figure 2). The results of the PCA were comparable to the cluster analysis. The first three components explained $43.05 \%$ of the total variation. 


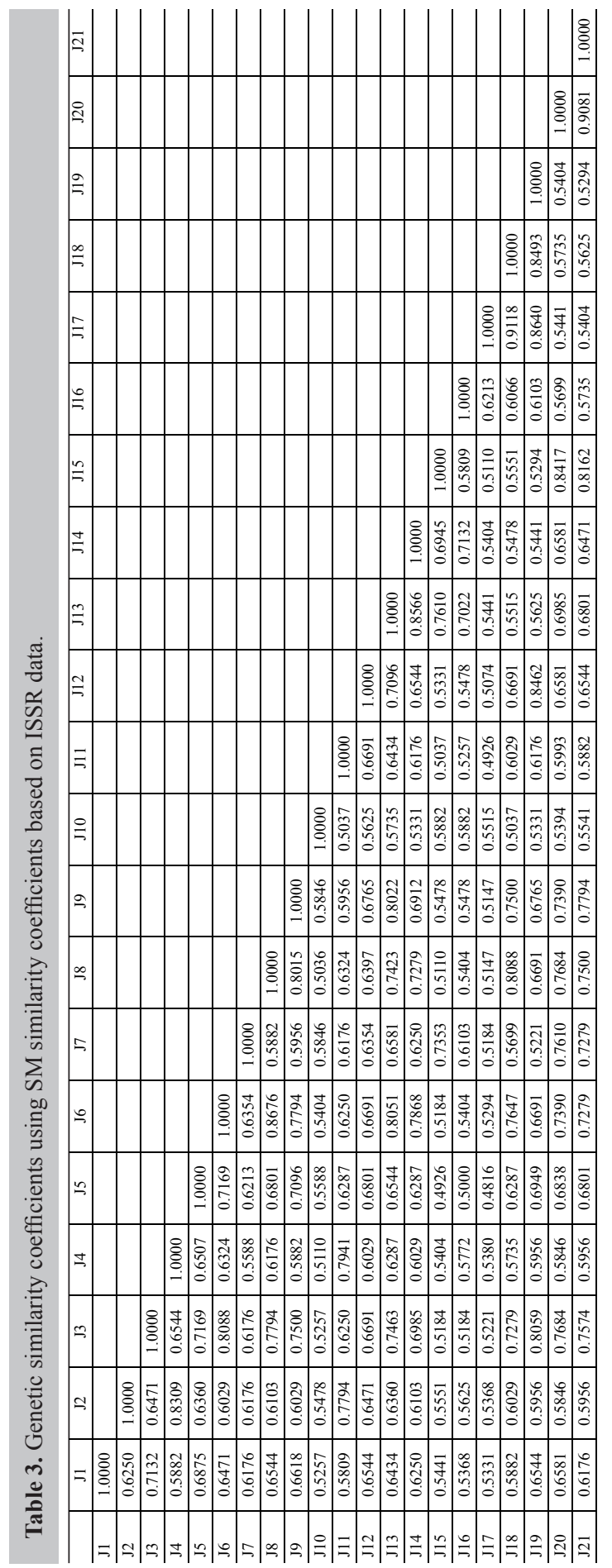

Genetics and Molecular Research 16 (1): gmr16019338 


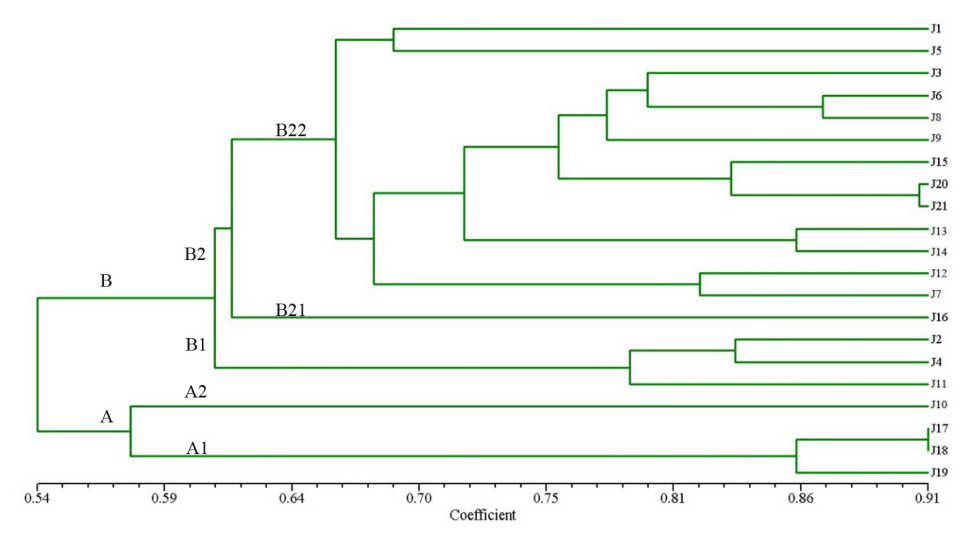

Figure 1. Dendrogram relationship of 21 accessions.

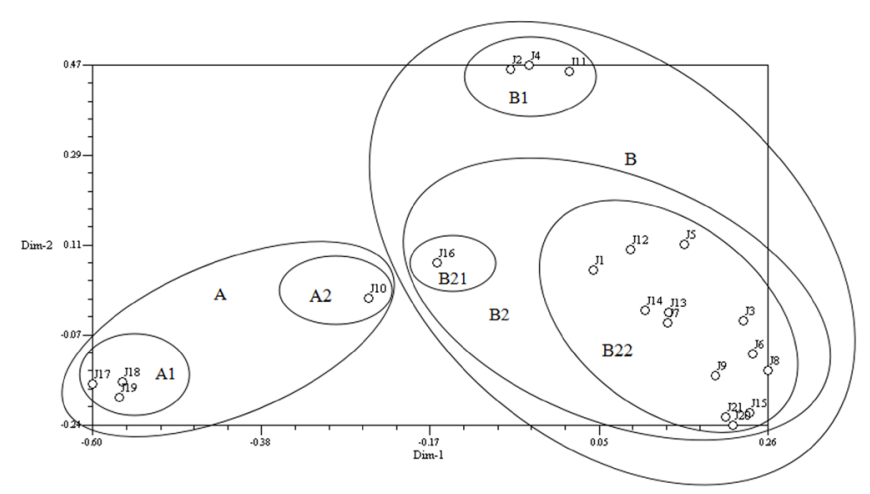

Figure 2. Two-dimensional plot (with vectors) of PCA of 21 accessions using ISSR.

\section{DISCUSSION AND CONCLUSION}

Molecular techniques have become a major tool for systems biologists, and they are useful for solving taxonomic problems at species and population levels. ISSR is widely used for germplasm identification and genetic diversity, genetic variation, and genetic relationship analyses.

When the genetic similarity coefficient is small, the genetic relationship is more distant. The similarity coefficient among accessions J17, J18, and J19 was very high, suggesting that these accessions belonged to the same species. However, for commercial applications, this variety was divide into three groups. Analysis of the UPGMA dendrogram clearly distinguished Lonicera japonica and Lonicera macranthoides, demonstrating that the ISSR markers could be effectively used to distinguish interspecific variations. In the Lonicera japonica cluster, the wild accession (J16) was distinguished from the other cultivars, demonstrating that the ISSR markers could also be effectively used to distinguish intraspecific variation. Therefore, these results provided insights into approaches for the selection of real Lonicera japonica germplasms for planting and established the wild germplasm is a new source for breeding.

In cluster A, accession J10 from Sichuan was distinguished from accessions J17, J18, and J19 from Shandong. The differences between the two subclusters may be explained by

Genetics and Molecular Research 16 (1): gmr16019338 
variations in soil and climatic conditions among regions. This is consistent with the results reported by Sun et al. (2013) and Han et al. (2013). In cluster B, subcluster B1 (including accessions J2, J4, and J11) shared common phenotypic features with young branches of Euonymus atropurpureus and young leaves of eggplant and exhibited red corolla. The other 14 accessions in B2 had white corolla. These results showed that the appearance of Lonicera japonica could be used as morphological classification features and that the ISSR results supported the morphological classification.

\section{REFERENCES}

Blair MW, Panaud O and McCouch SR (1999). Inter-simple sequence repeat (ISSR) amplification for analysis of microsatellite motif frequency and fingerprinting in rice (Oryza sativa L.). Theor. Appl. Genet. 98: 780-792. http:// dx.doi.org/10.1007/s001220051135

Charters YM, Robertson A, Wilkinson MJ and Ramsay G (1996). PCR analysis of oilseed rape cultivars (Brassica napus L. ssp. oleifera) using 5'-anchored simple sequence repeat (SSR) primers. Theor. Appl. Genet. 92: 442-447. http:// dx.doi.org/10.1007/BF00223691

Chen WC, Liou SS, Tzeng TF, Lee SL, et al. (2012). Wound repair and anti-inflammatory potential of Lonicera japonica in excision wound-induced rats. BMC Complement. Altern. Med. 12: 226-235. http://dx.doi.org/10.1186/1472-6882-12-226

Chen YY, Zhou RC, Lin XD, Wu KQ, et al. (2008). ISSR analysis of genetic diversity in sacred lotus cultivars. Aquat. Bot. 89: 311-316. http://dx.doi.org/10.1016/j.aquabot.2008.03.006

Cui XY (2011). The antiinflammatory and immunomodulation effects of the extract of Louicera Japonica Thunb. Chin. Pharm. 20: 8-9.

Gong CC, Zheng YX, Zheng NG, Cao Y, et al. (2006). Anti-oxidative effect of honeysuckle in vivo: An experimental study. Prac. J. Med. Pharm. 23: 584-585.

Han LN, Kang YQ, Guo QM, Zhou FQ, et al. (2013). ISSR-based genetic of Lonicerae Japonica in authetic region. $J$. Sichuan. Agric. Univ. 31: 414-418.

Kang OH, Choi YA, Park HJ, Lee JY, et al. (2004). Inhibition of trypsin-induced mast cell activation by water fraction of Lonicera japonica. Arch. Pharm. Res. 27: 1141-1146. http://dx.doi.org/10.1007/BF02975120

Li HY, Li ZY, Cai LY, Shi WG, et al. (2013). Analysis of genetic diversity of Ruthenia Medic (Medicago ruthenica (L.) Trautv.) in Inner Mongolia using ISSR and SSR markers. Genet. Resour. Crop Evol. 60: 1687-1694. http://dx.doi. org/10.1007/s10722-012-9950-3

Liang XY, Zhang HJ, Zhu LY, Luo Y, et al. (2011). Effects of extracts of Lonicera japonica Thunb. on hepatic PGC-1 $\alpha$ expression and insulin resistance in mouse. Chin. J. Diabetes 19: 197-200.

Liu YG, Liu YH and Jiang HQ (2012). Inhibitory effect and mechanism of polysaccharide from Lonicera japonica on mice bearing. J. Clin. Oncol. 18: 584-587.

Nie C, Liu R, Li S and Li Y (2014). Assessment of Platycodon grandiflorum germplasm resources from northern Anhui Province based on ISSR analysis. Mol. Biol. Rep. 41: 8195-8201. http://dx.doi.org/10.1007/s11033-014-3721-5

Rohlf FJ (2000). NTSYSpc: Numerical taxonomy and multivariate analysis system, version 2.10 user guide exeter software. Setauket. New York.

Smolik M, Ochmian I and Grajkowski J (2010). Genetic variability of Polish and Russian accessions of cultivated blue honeysuckle (Lonicera caerulea). Genetika 46: 1079-1085.

Sun ZY, Yao H, Wang ZZ, Bi YA, et al. (2013). ISSR analysis on genetic diversity of germplasm resource of Lonicerae Japonica. Mod. Trad. Chin Med. \& Mat. Med. 15: 1890-1895.

Sunar S, Yildirim N, Sengul M and Agar G (2016). Genetic diversity and relationships detected by ISSR and RAPD analysis among Aethionema species growing in Eastern Anatolia (Turkey). C. R. Biol. 339: 147-151.http://dx.doi. org/10.1016/j.crvi.2016.02.006

Tang M, Liu Y, Wang Y, Li D, et al. (2008). The in vitro antibacterial activity of the crude extract of total flavonoids from Lonicera japonica. Chin. Pharm. 19: 2321-2322.

Wang XY, He G, Wang XM and Qiao ZQ (2013). ISSR analysis on genetic variations among different varieties of Lonicera japonica. J. Centr. Sou. Univ. Forest. Tech. 33: 77-82.

Wang Z, Wang JE, Wang XM, Gao HW, et al. (2012). Assessment of genetic diversity in Galega officinalis L. using ISSR and SRAP markers. Genet. Resour. Crop Evol. 59: 865-873. http://dx.doi.org/10.1007/s10722-011-9727-0

Yan M, Wang YC and Xia DZ (1998). Effection of Flos Lonicerae co solution against herpes simplex virus 1 in vitro. Chin. J. Pract. 16: 82-84.

Yang CJ, Su DW, Wang YS, Zhang K, et al. (2012). Regulatory effect of honeysuckle on dysbacteriosis and endotoxemia in rats with obstructive jaundice. Chin. J. Micro. 24: 703-706.

Zietkiewicz E, Rafalski A and Labuda D (1994). Genome fingerprinting by simple sequence repeat (SSR)-anchored polymerase chain reaction amplification. Genomics 20: 176-183. http://dx.doi.org/10.1006/geno.1994.1151

Genetics and Molecular Research 16 (1): gmr16019338 